\title{
CULTURE BOUND SYNDROMES IN A GROUP OF XHOSA WITH PSYCHIATRIC DISORDERS
}

\author{
EN SHEZI and LR UYS
}

\section{ABSTRACT}

The article describes the culture bound syndromes found amongst a sample of 40 psychiatric patients seen at Umzimkulu Hospital serving mainly Xhosa speaking people. A CBS could be identified in 15 of these patients. CBS similar to four of the six syndromes found in these patients were described in DSM IV, while two were not. The CBS were compared to the Axis 1 diagnoses, and the different syndromes described.

\section{OPSOMMING}

Die artikel beskryf die kultuur gebonde sindrome (KGS) wat gevind is in steekproef van 40 psigiatriese pasiente van die Umzimkulu hospitaal, wat hoofsaaklik Xhosa sprekende mense bedien. In KGS is by 15 van hierdie pasiente gevind. Vier van die ses het ooreen gestem met KGS wat in die DSM IV beskryf is, en twee nie. Die KGS is met die As 1 diagnose vergelyk en die verskillende sindrome is beskryf

\section{PROBLEM STATEMENT}

The diagnosis and classification of mental disorders is an ongoing focus of psychiatric inquiry. Although it has long been recognised that mental disorders occur in people of all cultures, it is only in recent decades that the question of transcultural applicability of diagnostic schemas has been raised on an international level. DSM-1V is essentially an American document which still needs much testing in developing countried world wide. The question of its appropriateness in different cultural settings is still open (Jones and Kerson, 1988),

The new Diagnostic and Statistical Manual IV (DSM) was published in 1994. For this first time, a list of culture bound syndromes (CBS) were included. This refers to those disorders which are closely or exclusively associated with a particular population or culture. These conditions usually have an indigenous name, and are considred to indicate a need for attention or "cure".

This study specifically pertains to those syndromes described in DSM $-1 \mathrm{~V}$ and those found in the Xhosa population, and the research question was how culture bound syndromes, seen in a Xhosa population, correspond with those listed in DSM-1V, and how they correspond with Axis 1 diagnoses.

\section{SIGNIFICANCE OF THE STUDY}

The first prerequisite for an effective process of care is an accurate diagnosis to direct treatment and care. The DSM-1V provides valuable information and guidelines which may be used comfortably by different clinicians in the mental health field.

Research also depends on identifying groups of people with the same condition to be assigned to different methods of treatment and management. Without diagnostic groups no logical progress can be made. Epidemiology also relies on studying different groups of diagnoses to establish common aetiological factors in the hope of prevention and planning of required services (Hume and Pullen, 1986).

In this country, and perhaps in every country, the manifestation of mental illness is closely linked to cultural taboos, beliefs and superstition especially amongst more traditional groups in society. An understanding of racism, ethnic and cultural issues and repect for the individuals beliefs therefore underpins good practice in mental health care (Butterworth and Rushforth, 1995).

\section{TRANSCULTURAL ASPECTS OF PSYCHIATRY}

The American Psychiatric Association made special ef forts in the preparation of DSM-1V to incorporate an awareness that the manual is used in culturally diverse populations in the United States and internationally. In some instances it might happen that a clinician is not familiar with intricacies of an individuals cultural frame of reference and this may lead to incorrect judgement on those normal variations in behaviour, belief or experience that are specific to the individuals culture (APA, 1994).

Besides the universality of some mental disorders such as schizophrenia, depression and many others, cultural connotations are always present. Kluckhom in Foulks et al (1975) states that culture supplies the "blueprints" for human relations and that these blueprints are determinants of healthy and pathological patterns. So just as blueprints vary from culture to culture, though mental illness exists in all cultures, culture may determine the form in which it appears.

Paris (1994) mentions that crosscultural validity of psychiatric diagnoses is one of the problems of trans-cultu research hence APA (1994) has provided an Appendix culture bound syndromes and an outline for cultural Formulation to guide clinicians in the assessing of these syndromes. Although DSM-1V has provided two ways of increasing their recognition, it could still be true that it would be erroneous to attempt such diagnostic classification without empirical knowledge to underpin it (Yap, 1974).

To provide a broader understanding of cultural factors in mental illness it is appropriate here to look at some of the traditional views regarding mental illness.

Though there are different views, according to Cheetham and Griffiths (1980) and Cheetham and Rzadkowolski (1980) it is accepted universally that mental illness is relative to the culture concerned and mental illness concepts are based on beliefs regarding causation. North Americans include social norms with emphasis on willpower, dependence and environmental influences in aetiology. Germans see mental illness as entirely biological; the British subscribe to biological aetiology and the importance of independence; Hawaiian orientals are wary of their mentally ill and see them as victims of social factors.

South Africa is a pluralistic society and full of cultural diversities. Holdstock (1981) asserts that there are not many voices in Africa questioning those assumptions underlying the application of western scientific paradigms to the people of Africa. He cites Lambo as referring to the inadequacies of applying western mental health models based on western principles to the people of South Africa. Lambo attributed the reluctance to accept and respect the framework of the indigenous cultures to the unfortunate effect of 19th and 20th century Europe in setting European civilisation as the standard against which all others are to be measured.

Holdstock supported by Cheetham and Griffiths (1980) and Cheetham and Rzadkowolski (1980) admonishes the failure of the western world to understand the psychological principles underlying the life of the people of Africa and attributes this to lack of knowledge of the spiritual and psychological richness of black 
Africa. They commend strongly the holistic approach to life of black Africa which they claim differs considerably from the dichotomous reasoning of the westem world.

Le Roux (1973) shows a racist bias when he said that blacks are operating from a primitive thought system which is unlike the westem thought system. More often than not when a black consults a white doctor, he or she has already obtained explanations from the traditional healer and this may precipitate a paranoid delusional belief, which may lead to dangers of erring in cross cultural diagnosis and treatment. It should be noted that traditional healers are directive, unlike white clinicians who are non directive. Hence Daynes and Msengi, (1979) observed that patients always want to know why they are ill and who made them ill.

There also are problems in communication regarding translation or interpretation. Cheetham and Rzadkowolski (1980) write that "Considerations of biases, language and communication using the translator or interpreter and lack of fundamental knowledge of the culture and world view of the people is of concern. one finds a psychiatrist coming from a world of neurotransmitters, conflicts and defence mechanisms to the world of the Nguni tribalman of witchcraft, sorcery, ancestral beliefs and familiars". When translators interpret they often say that the patient is talking nonsense not understanding that it may be that very nonsense which may shed the light to a correct diagnosis (Buhrmann 1977: Cheetham and Griffiths 1980).

According to Cheetham and Griffiths (1980) the African concept of illness embraces biological, social, religious and magical factors. Symptoms from disorders are generally shaped by local beliefs, norms and general patterns of living. Psychiatric illness amongst the Nguni is primarily behavioural and interpersonally oriented with the above explanations. Medicine is the focal point around which all life events especially illness, disaster, economy and subsistence devolve. This was illustrated clearly by the tragedy of Nongqause and Mhlakaza when a vast number of Xhosas were destroyed in 19th century Transkei. The significance here is the intrinsic belief of the rural Xhosa in superstition, magic and witchcraft (Cheetham and Cheetham 1976).

Culture bound syndromes amongst the Xhosa are similar to those of the other Nguni groups and the differences may be only a matter of semantics. The 'igqira' (Xhosa word for sangoma or traditional healer) is essentially the diagnostician and therapist dedicated to the profession of healing and well being. The 'ixhwele' is purely a herbalist usually involved in sorcery (Cheetham and Cheetham 1980).

Basically amongst the South African blacks the common cultural syndromes are mainly "ufufunyane" and "ukuthwasa" based on the basic belief in the supernatural who is known as "umvelinqangi" meaning the first one who came into existence and the creator of everything. The ancestors are said to have gone to the world where this "Being" is. The Ithwasa is said to have a calling from the ancestors to be a traditional healer whilst a person may have bad spirits and said to be possessed with evil spirits

There is also a new development in faith healing in the religion of Zion where the Zionist is said to be possessed with spirits to become both faith healer and traditional healer (Filter and Bourquin, 1986 : Gangat, 1992).

\section{SETTING}

The study was conducted in Umzimkulu hospital which lies on the north eastern border of the Eastern Cape. It is a 550 bed facility. It is affiliated with a university, college of nursing, and a school of nursing and it was the only centre for psychiatric nurse training in the former Transkei. The population is mainly rural and is about 3 million. The language includes Xhosa, Zulu and Swazi dialects.

\section{RESEARCH DESIGN}

In this study the researcher compared the culture bound syndromes in the DSM-1V with those found in the sample. The sample consisted of the first 40 patients who were admitted to the hospital psychiatric units from the beginning of September 1995. The data collection was completed by the middle of November 1995 .

Personal interviews were conducted by a registered psychiatric nurse of Xhosa extraction, using the guidelines from Kaplan and Sadock (1994) and Skodol (1989).

Every culture bound diagnosis was identified as such, and an analysis of its correspondence with listed culture bound syndromes in DSM-1V was done.

\section{FINDINGS}

\section{Sample description}

The ages of the 40 patients sampled varied between 20 and 65 years with the majority in the younger age group i.e. $21-40$ years. The 25 males had an average age of 35.16 years and the 15 females averaged 39 years of age.
Regarding the level of education, $8 \%$ had no formal education whilst $63 \%$ had received formal education of between one and six years, which is seen as functionally illiterate.

The remaining $30 \%$ had formal education lasting $7-10$ years. A total of $92.5 \%$ was unemployed.

\section{Comparison of Culture Bound Syndromes}

In this sample most patients had a history of mental illness ranging from the past six months to two years and had not sought professional help.

Out of the forty patients, fifteen (38\%) showed evidence of culture bound syndromes. Seven of these were females, which is a high incidence, since there were only fifteen females in the sample. Of significance also, was that during history taking inquiries about the delay in seeking help were invariably answered with the information that the delay was due to first starting with the traditional healer where a culture bound diagnosis would be given

\section{TABLE 1 : DSM 1V CBS FOUND} AMONGST XHOSA PATIENTS

DSM-1V CBS
Rootwork
(USA, Carribean)
Amok
(South East Asia,
Mid-America)
Shin-byung
(Korea)
Spell
(USA)

XHosa name

Dliso
Meqo
No Xhosa Name
Thwasa
Uthandazeli/
Sangoma

Four of the CBS found in the sample corresponded roughly with descriptions given in the DSM IV (see Table 1), while two were not described in DSM IV (Thwala and Thwebula).

It is also interesting to compare the CBS with the Axis 1 diagnoses given (see Table 2). Amongst the males what emanates from these findings is that these syndromes mostly correlate with delusional and schizophrenic disorders whilst with the females it is mostly associated with mood disorders.

\begin{tabular}{|c|c|c|c|c|c|}
\hline \multirow[b]{2}{*}{ CBS } & \multirow{2}{*}{$\begin{array}{l}\text { TABLE 2: } \\
\text { SHIZ }\end{array}$} & \multicolumn{4}{|c|}{ AXS 1 DIAGNOSES OF PATENTS WITH CBS } \\
\hline & & MOOD & DEL & DUAL & TOTAL \\
\hline AMOK & 2 & & & & 2 \\
\hline THWALA & & & 1 & & 1 \\
\hline THEBULA & 1 & & & & 1 \\
\hline THWASA & 3 & 3 & 1 & & \\
\hline DLISO & 2 & & & 2 & 4 \\
\hline UTAND & & $1^{*}$ & & & $1^{\star}$ \\
\hline TOTAL: & 8 & 3 & 2 & 2 & 15 \\
\hline $\begin{array}{l}\text { Schiz: Schi } \\
\text { Del: Delus } \\
\text { ^One pers }\end{array}$ & $\begin{array}{l}\text {; Mood: M } \\
\text { order: Dual } \\
\text { o CBS. }\end{array}$ & $\begin{array}{l}\text { Disorder; } \\
\text { gnosis. }\end{array}$ & & & \\
\hline
\end{tabular}


Concerning women, this reminds one of Filter and Bourquin (1986) who explains the high proportion of women of sangomas amongst Zulu women by pointing out that most women are in polygamous marriages and being a sangoma brings back their dignity and respect. They gain recognition which they might have lost in a marriage where there may be four or five wives.

Dual diagnosis is also common amongst these cases especially with substance abuse, especially alcohol. For instance, the alcohol use may be said to be needed by the ancestor who has called the individual and may then be a necessary part of a rite. The individual may eventually present with toxic psychosis.

\section{Description of Culture Bound Syndromes:}

\section{Rootwork / Idliso / umeqo}

Here roots or spells or hexes can be placed on a person causing a variety of emotional and psychological symptoms. The person may fear death until the root is taken out. In Xhosa culture, the procedure described in DSM-IV is known as 'qubula.' if the root is taken off the person or 'mbulula' if taken out of the persons surroundings.

There were four patients with such syndromes. One of the patients said that he was feeling sick and he went to a traditional healer who told him that he had stepped over some substance which was strewn at the gate of his home and he was also fed something (idliso) by a familiar. He had to have these things removed. For making his home safe, he went to a traditional healer who came and dug out a bottle containing black stuff at his home and for the idliso he went to another one, who used her teeth on his stomach and several brown hard articles of a size of a maize seed came out.

Amok

Amok refers to a dissociative episode charaterized by a period of brooding after some perceived slight or insult, followed by a violent ouburst of egression. It is usually seen in men.

Two of the men had this syndrome. Most of the time they run away from home following some messages that they receive. They usually possess a lot of strength and may become aggresive when apprehended. This might be seen as part of the calling to be a traditional healer, and in such cases it might be called "ufufunuana".

One male patient recalled that, when he started to be ill, he started making groaning noises and then there was somebody who was calling his name from afar and was ordering him to come. It. was someone he knew from a nearby location.

\section{Shin-byung / Thwasa}

According to DSM-1V this is a Korean label for a syndrome in which the initial phases are characterised by anxiety and somatic complaints, leading up to possession by ancestral spirits. This is similar to the Thwasa syndrome as the individual also starts by having somatic complaints especially palpitations known as "uvalo" and will not eat and will have insomia. Seven patients had this syndrome.

One patient in the sample recalled "I started by having palpitations, became anxious and could not sleep nor eat. I was taken to a traditional healer who said I had intloko emhlophe." This is another word for Thwasa in Xhosa, meaning that the person is possessed by ancestral spirits. One patient said she received helpful messages from her late brother.

\section{Spell / Uthandazeli / sangoma}

This is a trance like state where the person is said to communicate with the dead and there are personality changes at that time. These individuals during that time have a change in the voice. If it is a female she talks with the voice of a male and is said to be speaking in the voice of the person whose spirit is possessing her at that time. In Xhosa patients this is part of the Sangoma role, when communication is with the ancestors. The umthandazeli is the cadre of prophets linked to African churches, and during the spell they communicate with God or the ancestors. This was described by only one patient, but it may be seen as part of the thwasa experience, especially in the later stages.

One of the patients said she was possessed with the spirit of her late grandfather. She recalled that when the spirit is coming she would first feel 'funny', then she would hear some noises in her ears and then she would fall down without total loss of consciousness. She would then speak in a deep voice which says at the beginning "Ndingu Roliyakayaka utatomkhulu wakho. Ndifuna ukusebenza ngawe." The voice then informed her to go to a certain mountain to go and dig some herbs to grind and use for healing the people. In some instances she would then sleep for one or two days without waking up.

\section{Thwebula}

Here the person is said to be taken by an 'aeroplane' of the witches : 'ikhetshi'. The person taken this way may become mentally ill if she or he escapes. Usually they do not return and are said to be made zombies.

One female gave such an account. This woman reported that two women from her neighbourhood came to her house in the late evening saying that they have come to take and make her a zombie but when she started to call the name of Jesus Christ, they left her.

\section{Thwala}

The person here is said to have gone to seek riches from a traditional healer and when the individual fails to carry out sinister rituals is said to become mentally ill.

There was one such patient. He reported that he had gone to a traditional healer in order to get rich, but after using some herbs at home that the traditional healer had given him he had to return to his place and have a bath in a room with snakes which were to lick him.

\section{Discussion of findings}

It is noted that religion and animism co-exist in this population and as cited in Uys (1994), South African blacks mostly subscribe to a dual approach to illness i.e. they combine traditional medicine and the western theory of medicine. For blacks, sickness, accidents and misfortune are caused intentionally by persons or personified beings and the hypothesis of chance or accident cannot be accepted as the final explanation of a misfortune.

\section{CONCLUSION and RECOMMENDATIONS}

In $38 \%$ of the sample mentally ill Culture Bound Syndromes could be identified. The rest of the sample had not been to a sangoma, and gave no history which corresponded to any of the Culture Bound Syndromes. Some of the Xhosa CBS corresponded to the DSM-1V list whilst others were unique to the Xhosa population.

The large numbers of CBS should be a strong motivation for the inclusion of culture bound syndromes in Axis 1 as a dual diagnosis. This will sensitize practitioners to these syndromes, and may promote more appropriate therapy for such patients.

The teaching of culture bound syndromes should be included in the curriculum of health workers, focusing mainly on the indigenous forms of the CBS.

Further research into culture bound syndrc: 23 is necessary. Questions about whether paten's with such a diagnosis have a different illness trajectory and whether a culturally appropriate regime gives improved success in these cases, should be investigated.

\section{REFERENCES}

American Psychiatric Association. (1994) Diagnostic \& Staristical Manual of Mental Disorders -4 th ed. Revised. Washington DC : Anerica Psychiatric Association.

Buhrmann, M. V. (1977). Westem Psychiatry and the Xhosa Patient South African Medical Joumal-51. 464 .

Butterworth, T. \& Rushforth, D.(1995). Working in Partnership with people who use services Reaffirming the practice for Mental Health Nursing. Inter _L_vius. Sind 32.373 - 385

Cheetham, R. W. S. \& Cheetham, R. J. (1976). Concepts of Mental lllness amongst the Rural Xhosa People in South Africa. Australia and New Zealand Lurnal of Psychiatry. 10 (39) 3944

Cheetham, R. W. S. \& Griffiths, J. A. (1980). Changing Patterns in Psychiatry in Africa with special reference to South Africa South_African_Medical Joumal 7.-166-16.

Cheetham, R. W. S. \& Rzadkowolski, A. (1980). Crosscultural Psychiatry and the Concept of Mental Ilness. South African Medical Joumal 58.320 325. 
Dayoes, G. \& Msengi, N. P. (1979). Why am I ill? Who made me ill? The relevance of Westem Psychiatry in Transkei. Suid Afrikaanse Mediese-Tydskrif. 7,307-308.

Fllter, H. \& Bourquin, S. (1986). Paulina Dlamini. Servant of two Kings. Durban: Killie Campbell Africana Library and Pietermaritzburg : University of Natal Press.

Gangat, A. T. (1992). Psychosis and its Management Durban: Atlas Printers.

Holdstock, T.L. (1981). Psychology in South Africa belongs to the Colonial era. Arrogance or Ignorance? South African Joumal of Psychology, 11, 123-129.

Hume, C. \& Pullen, I. (1986). Rehabilitation in Psychiatry anIntroductory Handbook. New York: Churchill Livingstone.

Jones, B. \& Kerson, D. (1988). Tertiary Care in Zaire : DSM 111 in the Developing World. The Intemational Jounal of Psychiatry 34 (1), 31-39.
Kaplan, H. I. \& Sadock, B. J. (1994). Synepsis of Esychiatry London: Williams \& Wilkins.

Kluckholm, D. (1978). The funure of Cultura Psychiatry in Eoulks E.\& Wintrob. R.\& Westemeyer L. \& Earazza. A.Current Perspective in Cultural Psvchiatry New York : Saunders Co

Le Roux, A. G. (1979). Psychological Factors in Bantu Culture South African Medical Joumal, 47 2077-2083.

Le Roux, A. G. (1979). Psychological factors in the Health of South, African Blacks. South African Medical Joumal, (13),532- 534.

Paris, J. (1994). Evolutional Social Science and Transcultural Psychiatry. Iransculnural Psychaitric research Reiview. 21

Skodol, A. E..(1989). Broblems-of Differential Diagnosis From DSM- 111 to DSM-111-R in Clinical Practice, Washington DC: American Press.
Yap, P. M. (1974). Comparative Psychiamy. Canada: University of Toronto Press.

EN Shezi M.CUR
Umzimkulu Hospital
LR Uys D.Soc.Sc
Professor:
Head : Department of Nursing
University of Natal (Durban)

